\title{
Research on mechanical properties and acoustic emission characteristics of rock beams with different lithologies and thicknesses
}

\author{
Tong-bin Zhao ${ }^{a, b}$ (D) Peng-fei Zhang ${ }^{a, b}$ (D) Wei-yao Guo ${ }^{a, b, *}$ (D), Ya-xun Xiaoc (D), \\ Yong-qiang Zhaod (D), Xiang Sun ${ }^{\mathrm{e}}$ (I)
}

${ }^{a}$ College of Energy and Mining Engineering, Shandong University of Science and Technology, Qingdao 266590, China. Email: ztbwh2001@163.com; 15064221133@163.com; 363216782@qq.com

${ }^{b}$ State Key Laboratory of Mining Disaster Prevention and Control Co-founded by Shandong Province and the Ministry of Science and Technology, Shandong University of Science and Technology, Qingdao 266590, China;

c State Key Laboratory of Geomechanics and Geotechnical Engineering, Institute of Rock and Soil Mechanics, Chinese Academy of Sciences, Wuhan, 430071, China. Email: yxxiao@whrsm.ac.cn

${ }^{d}$ State Key Laboratory of Water Resource Protection and Utilization in Coal Mining, Beijing 102209, China. Email: 20039429@chnenergy.com.cn

e Shandong Energy Group Co., Ltd., Jinan 250014, China. Email: 5905383@163.com

* Corresponding author

https://doi.org/10.1590/1679-78256711

\begin{abstract}
The lithology and thickness of the rock beam affect its mechanical properties and acoustic emission characteristics when it is fractured. In this study, three-point bending tests of rock beams were carried out. Then, we proposed to utilize the percentage of peak energy to characterize the intensity of energy release during fracture. Finally, the energy release mechanism of coal roof fracture was discussed. The evolution process of acoustic emission includes five stages. The acoustic emission amplitude distribution of rock beams has three typical patterns. Most of the cracks after fracture are tensile cracks, the proportion of tensile cracks is positively correlated with the elastic modulus. The percentage of peak energy is positively correlated with thickness and elastic modulus. More energy is released when thick and hard roof fractures. When necessary, measures such as reducing the thickness or the strength of the roof could be taken to improve the safety of mining.
\end{abstract}

\section{Keywords}

Rock beam fracture; three-point bending test; acoustic emission; AE energy; crack mode

\section{Graphical Abstract}
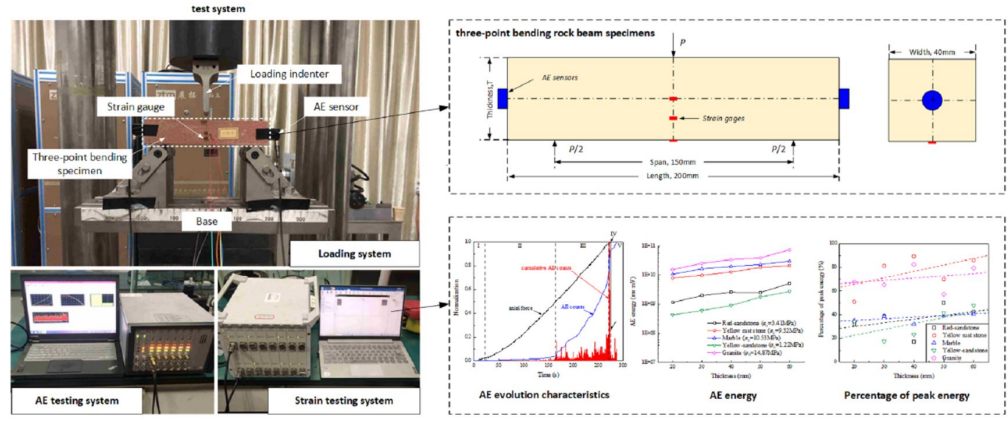


\section{INTRODUCTION}

At present, coal mining is deeply threatened by rock bursts (Zhao et al. 2018a; Zhao et al. 2018b; Zhao et al. 2021). Generally, rock burst can be divided into four types according to different disaster mechanisms: coal pillar instability, fault slip, fold structure and roof fracture (Pan et al. 2003; Lu et al. 2018; Yu et al. 2018; Hu et al. 2017). Among them, the roof fracture-type rock burst has the characteristics of high occurrence frequency, large impact strength and massive energy release, which seriously threatens the production safety of coal seam (Tan et al. 2021; Guo et al. 2019a). Many studies (Marcak 2012; Zhao et al. 2018c) have shown that thick and hard roof is a typical geological condition that induces roof fracture-type rock burst, and the large amount of energy released by fracture under the action of bending load is the root cause of roof fracture-type rock burst. Therefore, the mechanical properties and energy release laws of rock beams with different lithologies and thicknesses under bending loads are issues of great concern in the field of coal mining engineering.

In recent years, many scholars have tried to explain the mechanical properties of roof fracture by theoretical analysis (Yang et al. 2011; Zhou et al. 2011) and field measurements (Lu et al. 2019; Guo et al. 2017). However, research at the current stage of engineering scale is limited to quantitative analysis due to many on-site influencing factors. On the contrary, the theoretical analysis method usually ignores the influence of some factors in the process of solving, which makes the research results have certain limitations. Therefore, more researches of the rock beam fracture problems are carried out by lab experiments and numerical simulations.

In lab experiments, three-point (Dong et al. 2017; Stavrakas et al 2016) and four-point (Ayatollahi et al. 2013; Efimov 2011; Koudelka et al. 2020) loading are generally used to provide bending loads for rock beams. AE (Acoustic Emission) test is a very effective method to study the fracture of rock beams. It has significant effects on the research of crack propagation (Bing and Einstein 2017; Du et al. 2018; Cao and Liu 2020), damage mechanism (Wu et al. 2020) and failure precursor information (Guo et al. 2019b; Guo et al. 2019c) of rock beams. Zhang et al. (2019) analyzed the damage evolution mechanism of limestone beams based on the AE characteristics under bending load. Zhang et al. (2015) used the method of combining AE and DIC to study the deformation and failure process of sandstone rock beam specimens under three-point bending load, and reached similar conclusions with Wang et al. (2018). Both Li et al. (2020) and Du et al. (2020) analyzed the distribution of RA-AF obtained in the AE test, and studied the classification of cracks in the process of rock beams fracture.

In addition, some studies on the fracture mechanism of rock beams have been carried out using numerical simulations. For example, Xi et al. (2020) based on the non-local extended finite element method and mixed-mode rock fracture model, it is concluded that the rock beam fracture energy is highly correlated with the peak load. Zhao et al. (2018) introduced the three-point bending model into the engineering site, and analyzed the instability process of the rock beams by FLAC3D.

Although the above studies all involve the mechanical properties and the energy release laws of rock beam, the main research object is a single type of rock beam specimens. Whether the lithology and thickness of the rock beam will cause the mechanical behavior and energy release characteristics to change when it fracture, which will affect the engineering, is still unconfirmed. Therefore, this study carried out three-point bending tests of rock beams with different lithologies and thicknesses, obtained the influence of lithology and thickness on the mechanical properties, and described the fracture process and characteristic of different rock beams based on multiple parameters in the AE test. In addition, a parameter that characterizes the intensity of energy release when the rock beams fracture is proposed, and the energy release mechanism of the rock beams fracture in the roof of the coal seam is discussed. This study can provide a theoretical basis for the occurrence mechanism and control measures of roof fracture-type rock burst.

\section{SPECIMEN PREPARATION AND TEST SCHEME}

\subsection{Specimen preparation}

In order to study the mechanics and energy release characteristics of rock beam when it fractures, three-point bending tests of rock beams with different lithologies and thicknesses is carried out. Five types of rocks were processed in the test, namely red-sandstone, yellow rust stone, marble, yellow-sandstone, and granite. Rock specimens of the same lithology are cut from the same piece of rock. They were processed into rectangular cross-section beam-shaped specimens, and surface flatness of specimens were processed again to make the processing accuracy meet the ISRM standard, as shown in Figure 1. Before the bending test, the physical and mechanical parameters of different lithologies were tested, including density, compressive strength, tensile strength, elastic modulus, shear wave velocity and longitudinal wave velocity. The test results are shown in Table 1. 


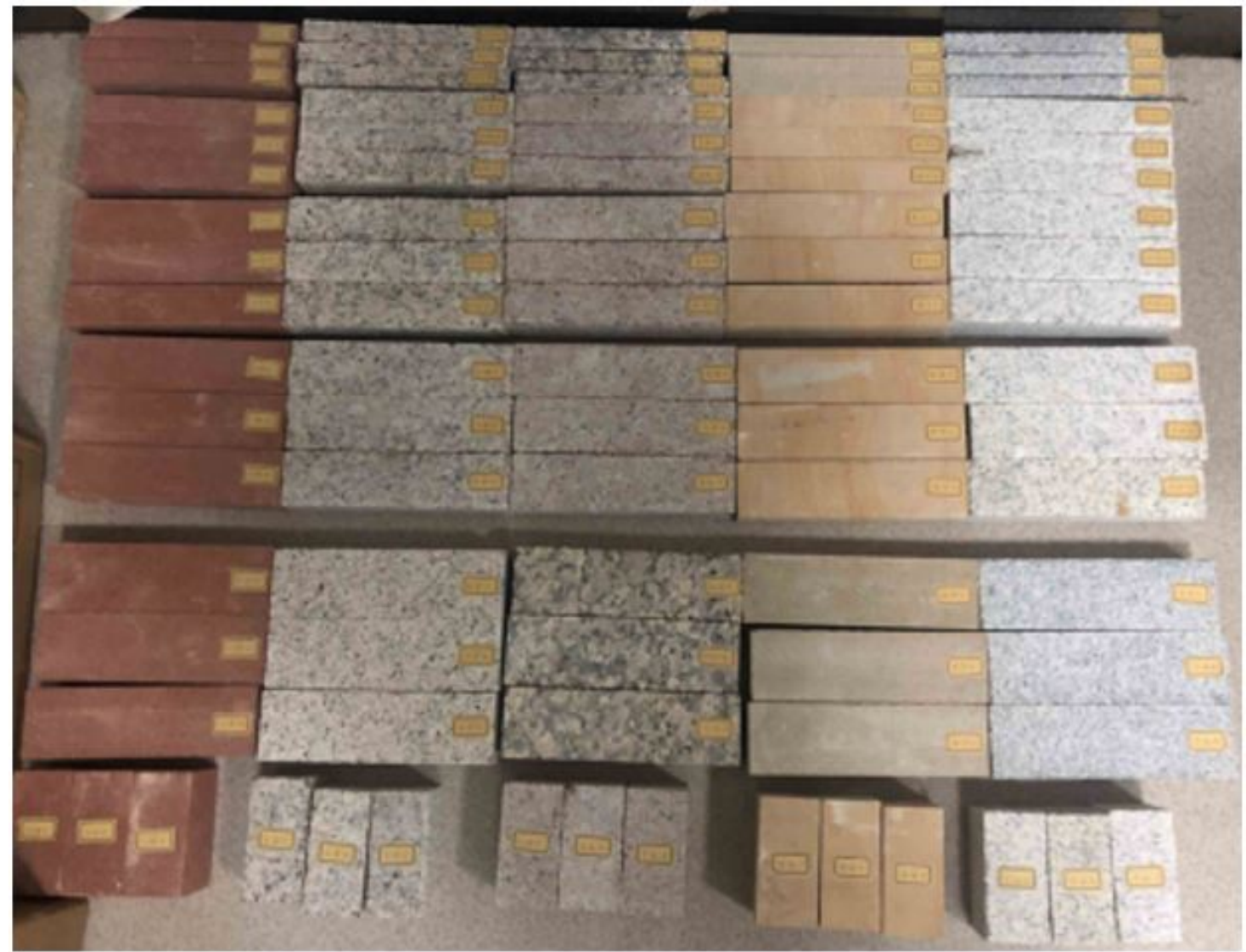

Figure 1 Rock specimens of three-point bending and uniaxial compression.

Table 1 Physical and mechanical parameters of rock beams.

\begin{tabular}{ccccccc}
\hline Lithology & $\begin{array}{c}\text { Density } \\
(\mathbf{g} \cdot \mathbf{c m}-\mathbf{3})\end{array}$ & $\begin{array}{c}\text { Compressive } \\
\text { strength (MPa) }\end{array}$ & $\begin{array}{c}\text { Tensile } \\
\text { strength (MPa) }\end{array}$ & $\begin{array}{c}\text { Elasticity } \\
\text { modulus (GPa) }\end{array}$ & $\begin{array}{c}\text { Shear wave velocity } \\
\text { (m/s) }\end{array}$ & $\begin{array}{c}\text { Longitudinal } \\
\text { wave velocity } \\
\text { (m/s) }\end{array}$ \\
\hline Red-sandstone & 2.57 & 35.85 & 3.41 & 5.68 & 1733.85 & 2486.02 \\
Yellow rust stone & 2.81 & 99.94 & 9.32 & 12.31 & 3304.15 & 3805.90 \\
Marble & 2.69 & 93.47 & 10.53 & 10.07 & 2706.36 & 4744.96 \\
Yellow-sandstone & 2.47 & 36.15 & 1.22 & 4.13 & 2301.50 & 3593.89 \\
Granite & 2.87 & 152.51 & 14.87 & 14.13 & 3802.28 & 4722.55 \\
\hline
\end{tabular}

\subsection{Test scheme and equipment}

In order to systematically study the mechanical properties of different types rock beams, the effects of lithology and thickness were considered in the test. To ensure the accuracy of the test, three identical specimens were prepared for each scheme. Table 2 shows the ID and parameter information of each specimen. Strain gauges and AE sensors were arranged on the surface of the specimen to monitor the changes of strain and AE signals during the experiment, as shown in Figure 2.

Table 2 Specifications for three - point bending beam specimens.

\begin{tabular}{ccccc}
\hline Specimen ID & Lithology & Length $(\mathbf{m m})$ & Width $(\mathbf{m m})$ & Thickness $(\mathbf{m m})$ \\
\hline $1-1,2,3,4,5$ & Red-sandstone & 200 & 40 & $20,30,40,50,60$ \\
$2-1,2,3,4,5$ & Yellow rust stone & 200 & 40 & $20,30,40,50,60$ \\
$3-1,2,3,4,5$ & Marble & 200 & 40 & $20,30,40,50,60$ \\
$4-1,2,3,4,5$ & Yellow-sandstone & 200 & 40 & $20,30,40,50,60$ \\
$5-1,2,3,4,5$ & Granite & 200 & 40 & $20,30,40,50,60$ \\
\hline
\end{tabular}



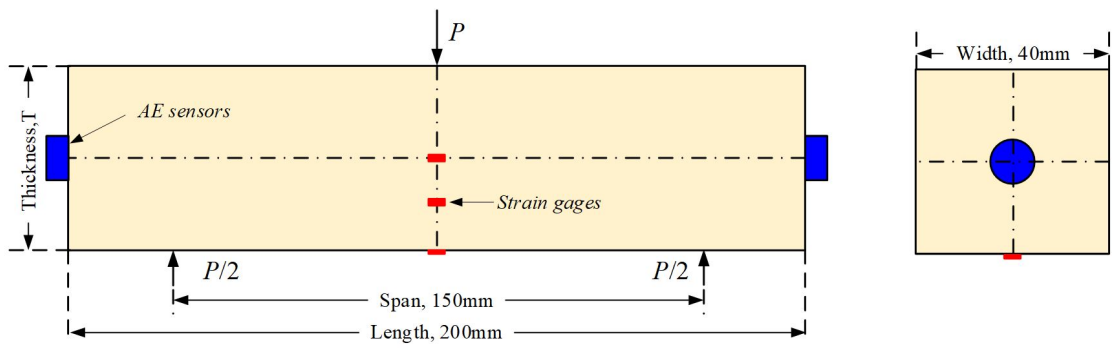

Figure 2 Sketch of three-point bending rock beam specimens.

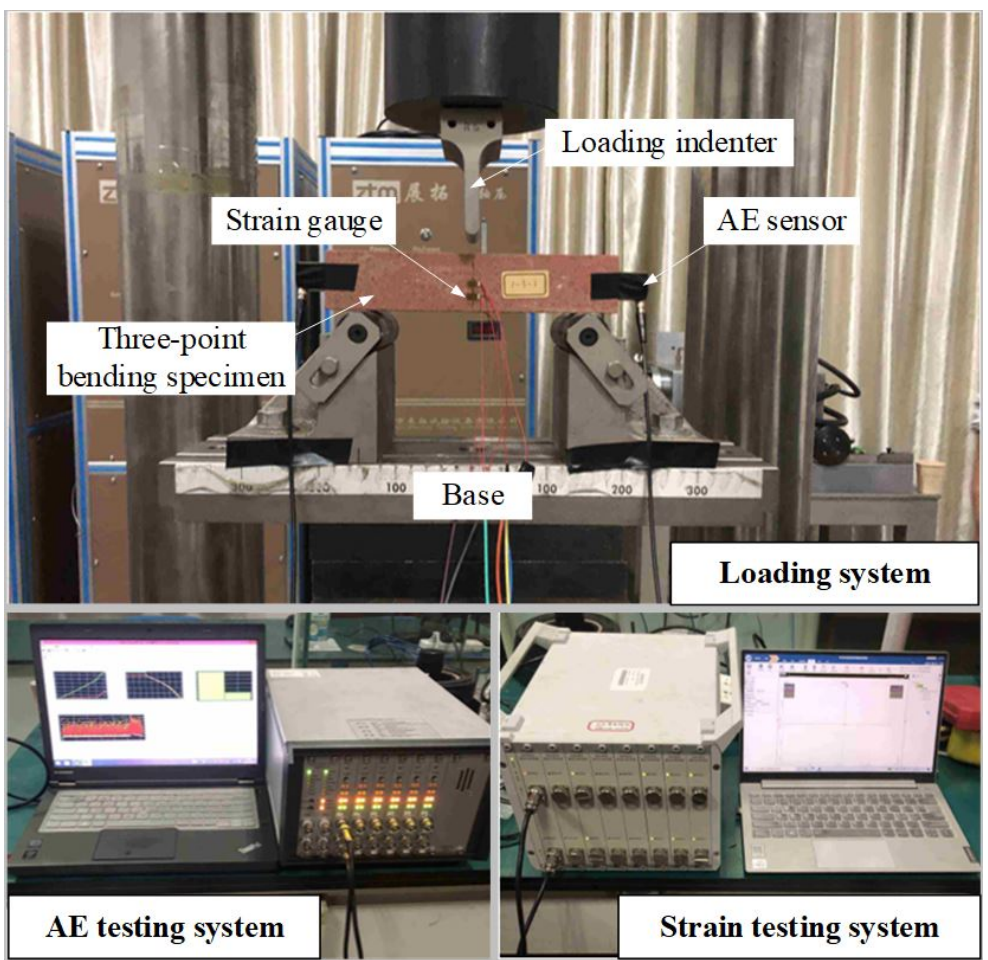

Figure 3 Sketch of test system.

The test system includes the loading system, the AE testing system and the strain testing system, as shown in Figure 3. These tests were conducted using an RLJW-2000 servo-controlled rock pressure testing machine, which can provide a maximum axial force of $2000 \mathrm{kN}$, a sampling frequency of $10 \mathrm{hz}$, and a sampling accuracy of $\pm 1 \%$. In the tests, the loading rate is $0.05 \mathrm{~mm} / \mathrm{min}$. Two AE sensors were arranged on the surface of each specimen. The AE test equipment is an AMSY-6 acoustic emission system produced by Vallen. The test frequency, the preamplifier gain and the threshold are $10 \mathrm{Mhz}, 34 \mathrm{~dB}$ and $40 \mathrm{~dB}$, respectively. Vaseline was used to improve the coupling between the $A E$ sensor and the specimen. The sampling frequency of the strain testing system is set to $20 \mathrm{~Hz}$ to match with the testing machine. The strain gauges are connected by a quarter bridge, and the temperature compensation gauges is connected at the same time to offset the influence of different temperature and material.

\section{BASIC MECHANICAL PROPERTIES}

\subsection{Load-deflection and stress-strain curves}

Figure 4 shows the load-deflection curves of five kinds of rock beams, which are quite different each other. The prepeak curves of the red-sandstone and yellow-sandstone specimens are approximately linear, while the pre-peak curves of the other three types of rock beams have obvious upward concave characteristics. Because granite, marble and yellow rust stone are composed of larger crystalline particles, they show obvious compaction characteristics in the test. The post-peak curves of all rock beams show the characteristics of brittle fracture, and the post-peak residual strengths are much lower than the peak loads. The load-deflection curves of rock beams with different thicknesses are similar, but the peak load and deflection at peak load are obviously different, both of which are positively correlated with the thickness. 


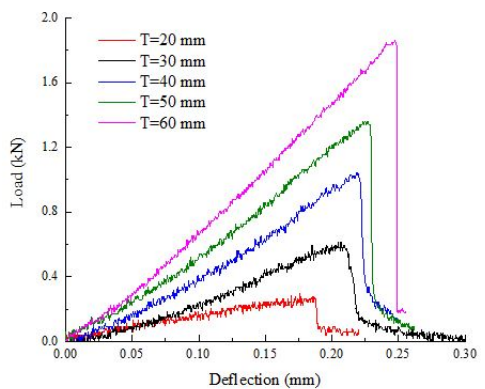

(a)

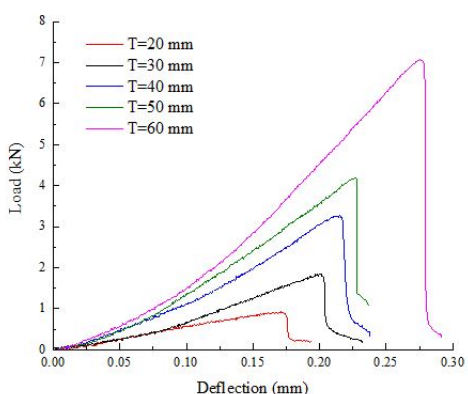

(b)

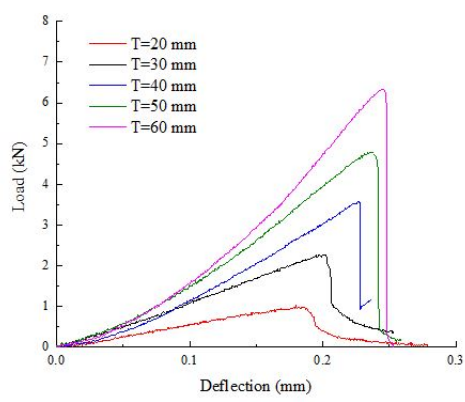

(c)

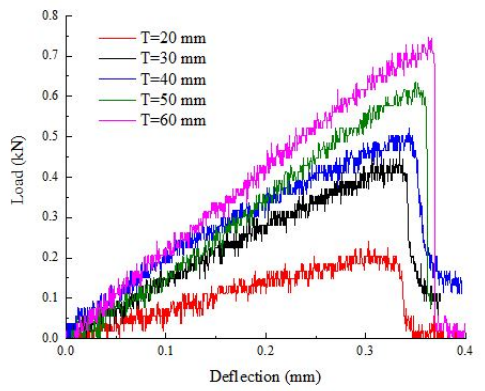

(d)

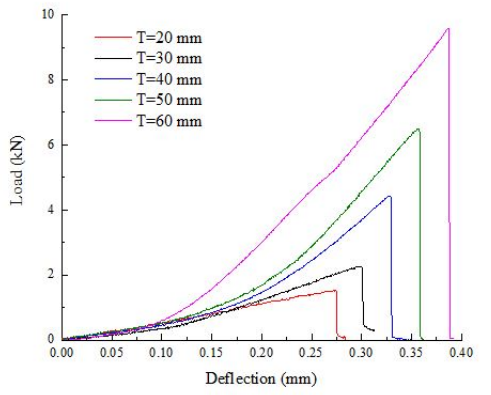

(e)

Figure 4 Load-deflection curve: (a) red-sandstone; (b) yellow rust stone; (c) marble; (d) yellow-sandstone;(e) granite.

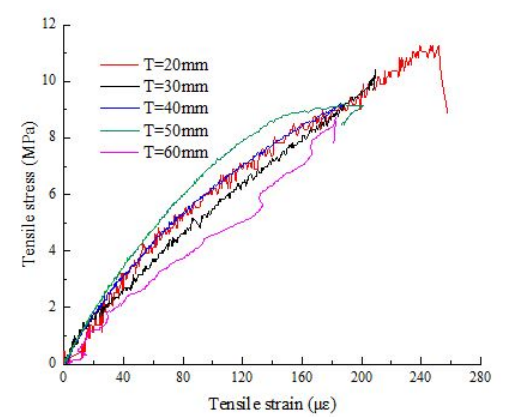

(a)

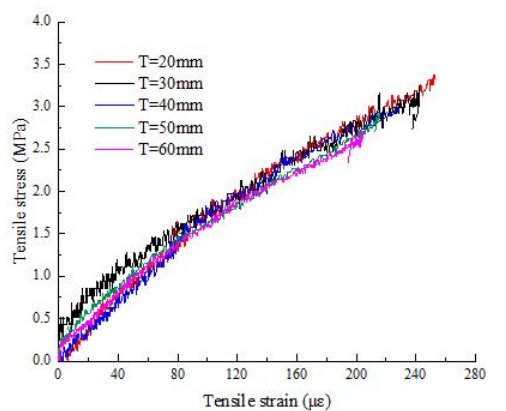

(b)

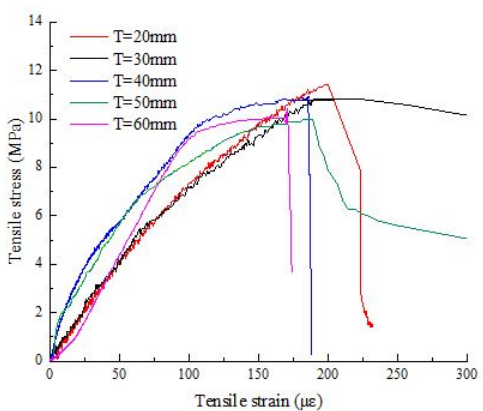

(c)

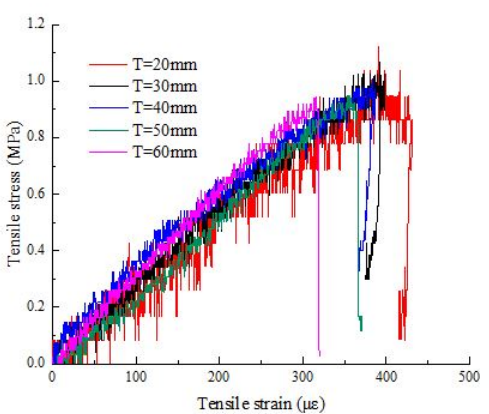

(d)

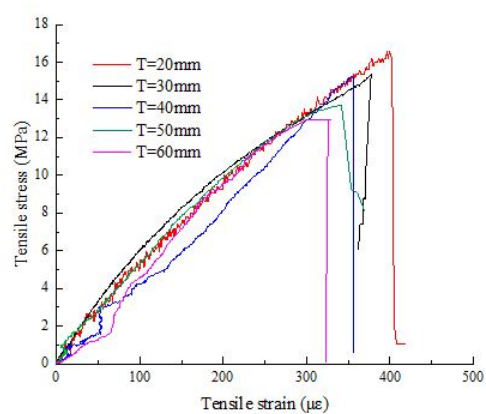

(e)

Figure 5 Stress-strain curve: (a) red-sandstone; (b) yellow rust stone; (c) marble; (d) yellow-sandstone; (e) granite.

In order to analyze the stress-strain relationship of the three-point bending rock beams, the tensile stress and tensile strain at the bottom midpoint of the rock beam are obtained according to the test results, as shown in Figure 5 . During the data processing, the original data measured by the strain gauge is used as the tensile strain at the corresponding position of the rock beam, and the tensile stress of the rock beam is calculated according to the vertical load value monitored by the testing machine (Ju et al. 2021). The calculation formula is shown as Eq.(1): 
$\sigma_{x}=\frac{M}{I_{z}} y=\frac{3 P l}{b h^{3}} y$

In Eq.(1), $P$ is the axial force of the three-point bending, $I$ is the span between the two loading points at the bottom, $b$ is the width of the beam, $h$ is the thickness of the beam, and $y$ is the position of the calculated tensile stress.

The shape of the pre-peak part of the stress-strain curve changes with lithology. It is approximately linear for the low-strength rock beam, while obviously concave downwards for the high-strength rock beam. The peak tensile stresses of rock beams with different lithologies are quite different. The peak tensile stress of granite is more than 13 times that of the yellow sandstone. This fully reflects the difference in tensile strength of different lithologies.

\subsection{Mechanical parameters and failure modes}

Figure 6a shows the tensile strength of different rock beam specimens. Obviously, thickness and lithology of the specimens affect the magnitude of the tensile strength. The tensile strength of the $20 \mathrm{~mm}$ granite rock beam is 16.61 MPa, while the $20 \mathrm{~mm}$ yellow-sandstone rock beam only $0.94 \mathrm{MPa}$. The variation of tensile strength shows obvious size effect. As the thickness increases, the tensile strength of the rock beam decreases, which is very obvious on the yellow rust stone specimens. The tensile strength of the $20 \mathrm{~mm}$ specimen is 1.29 times that of the $60 \mathrm{~mm}$ specimen. In addition, the tensile strength is obviously affected by the lithology of the rock beam. The tensile strength of redsandstone and yellow-sandstone are significantly lower than those of the other three lithologies.

Figure $6 \mathrm{~b}$ shows the maximum tensile strain at fracture of different rock beam specimens. The maximum tensile strain of the $20 \mathrm{~mm}$ granite rock beam is about $0.396 \times 10^{-3}$, while that of the $60 \mathrm{~mm}$ marble rock beam is only $0.171 \times 10^{-3}$. The maximum tensile strain is also negatively correlated with the thickness of rock beam, which means that the thinner beam needs to be bent to a higher degree before it can be fractured. In addition, lithology also affects the maximum tensile strain. The yellow-sandstone and granite are obviously higher than the other three lithologies, indicating that the yellow-sandstone and granite have better bending resistance than the other three rock beams.

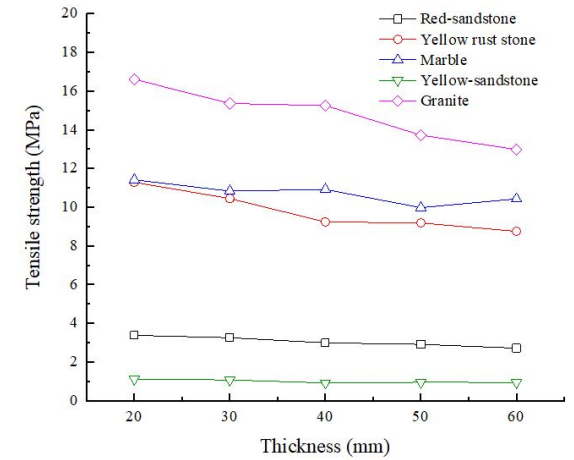

(a)

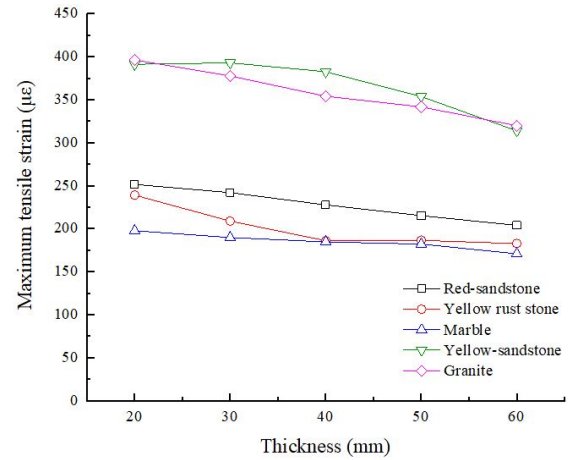

(b)

Figure 6 Test results of different rock beam specimens: (a) tensile strength; (b) maximum tensile strain.

\section{INFLUENCE OF ROCK LITHOLOGY AND THICKNESS ON AE CHARACTERISTICS}

\subsection{Influence of rock lithology}

Figure 7 shows AE counts evolution of rock beam specimens with different lithologies. The data were normalized during the analysis process. This process can be simply summarized as: divide each set of data by the maximum value to obtain a new set of dimensionless data in order to summarize the characteristics. The AE characteristics in the fracture process of a rock beam can be divided into five stages, the calm stage, the development stage, the incremental stage, the explosive stage and the residual stage. Rock beams all have a sharp increase in AE when they reach the peak load, but the AE characteristics before the peak load are slightly different. The AE development stage of red-sandstone and yellow-sandstone lasted longer, which is believed to be related to the large number of tiny primary cracks. The rock beam with a large elastic modulus shows brittle fracture in the AE characteristics. There is no obvious increase in AE counts in the early stage of loading, and a large number of AE signals erupt when the specimen failed. For example, when the granite sample reaches the peak load, the instantaneous AE count is more than 2.6 times the cumulative total in the previous period. 


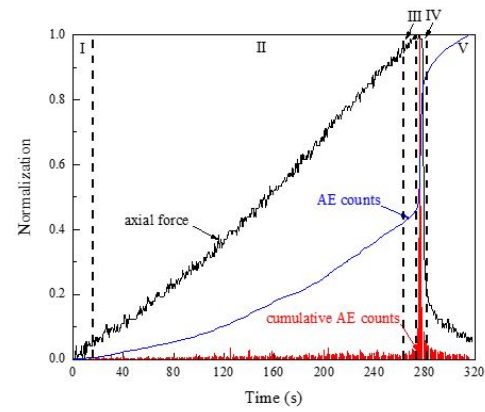

(a)

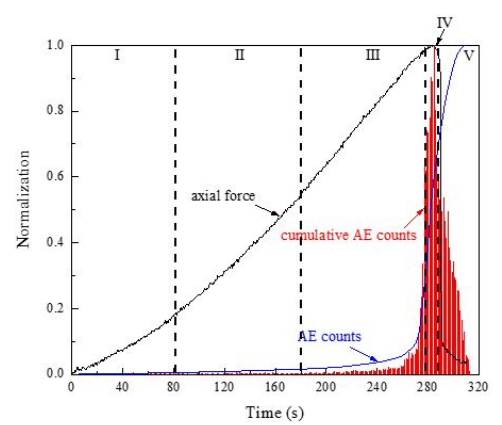

(b)

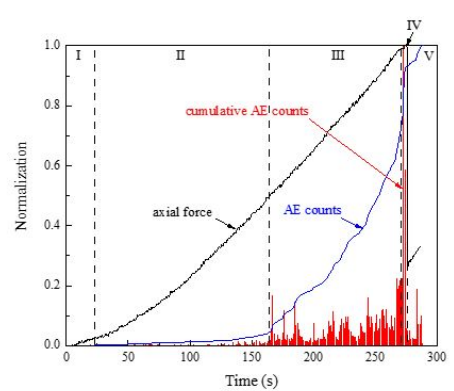

(c)

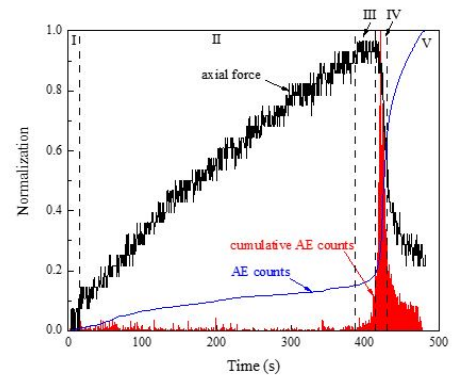

(d)

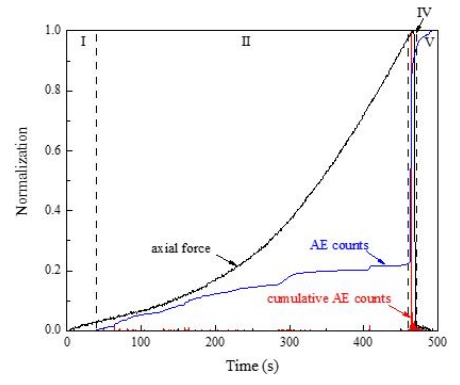

(e)

Figure $7 \mathrm{AE}$ evolution characteristics of three-point bending rock beams with different lithologies: (a) red sandstone; (b) yellow rust stone; (c) marble; (d) yellow sandstone; and (e) granite.

The $A E$ amplitude refers to the peak amplitude of an $A E$ signal. Figure 8 shows the distribution of the AE amplitude during the loading process of the rock beams. The AE amplitude distributions of five kinds of lithological rock beams are very different, and can be roughly divided into three categories: 'low-low-low', 'high-low-high', and 'high-high-high'. Taking sandstone as an example, the amplitude distribution of the first type of rock beam during the fracturing process is relatively uniform, mainly concentrated in $40-60 \mathrm{~dB}$. It shows that the AE signal released by the crack propagation of rock beam is relatively weak, mainly with low amplitude (less than $60 \mathrm{~dB}$ ). The second type of rock beam takes marble and granite as examples. In addition to more AE counts in the low-amplitude area, a large number of AE counts also appeared in the high-amplitude area (with an amplitude greater than $90 \mathrm{~dB}$ ). It is worth noting that these two lithological rock beams exhibit stronger brittleness characteristics when fractured. This matches with the distribution law of $A E$ amplitude during the loading process of the specimens. The third type of rock beam takes yellow rust stone as an example, with a large number of AE signals distributed between 50 and $100 \mathrm{~dB}$ in amplitude. This indicates that strong $A E$ signals have been accompanied by the rock beam loading process. Most of these AE signals originate from the crack propagation and crystal particles ifriction inside the rock beam.

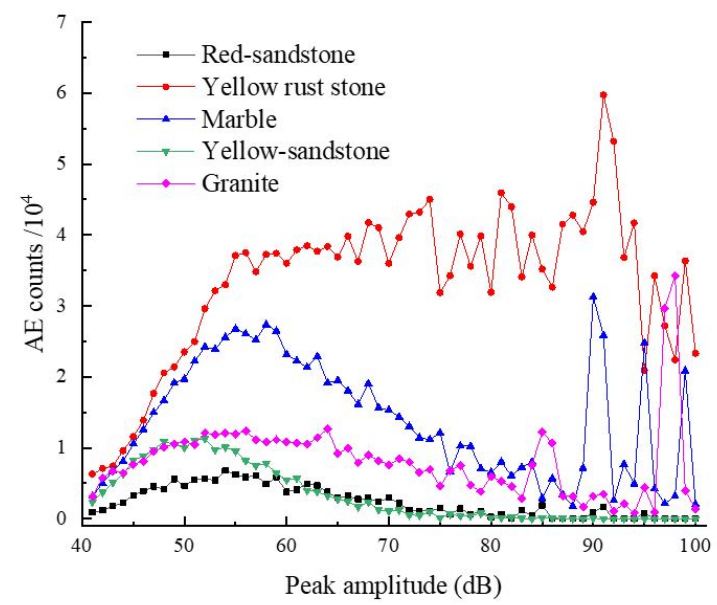

Figure $8 \mathrm{AE}$ peak amplitude distribution characteristics of three-point bending rock beams of different lithologies. 
$A E$ duration refers to the duration of an $A E$ signal exceeding the preset threshold ( $40 \mathrm{~dB}$ ). Figure 9 shows the distribution of $A E$ duration of different lithological rock beams. It can be seen that the duration of most $A E$ events is greater than $100 \mu \mathrm{s}$. Among them, the AE duration of the two kinds of sandstone is concentrated in $100 \sim 1000 \mu \mathrm{s}$. For rock beams with higher strength, $\mathrm{AE}$ duration is distributed between a larger range of 1000 to $10000 \mu \mathrm{s}$, and the $\mathrm{AE}$ counts is significantly more than that of sandstones. This shows that as the strength of the rock beam increases, the strength of the AE signals becomes greater and the duration becomes longer.

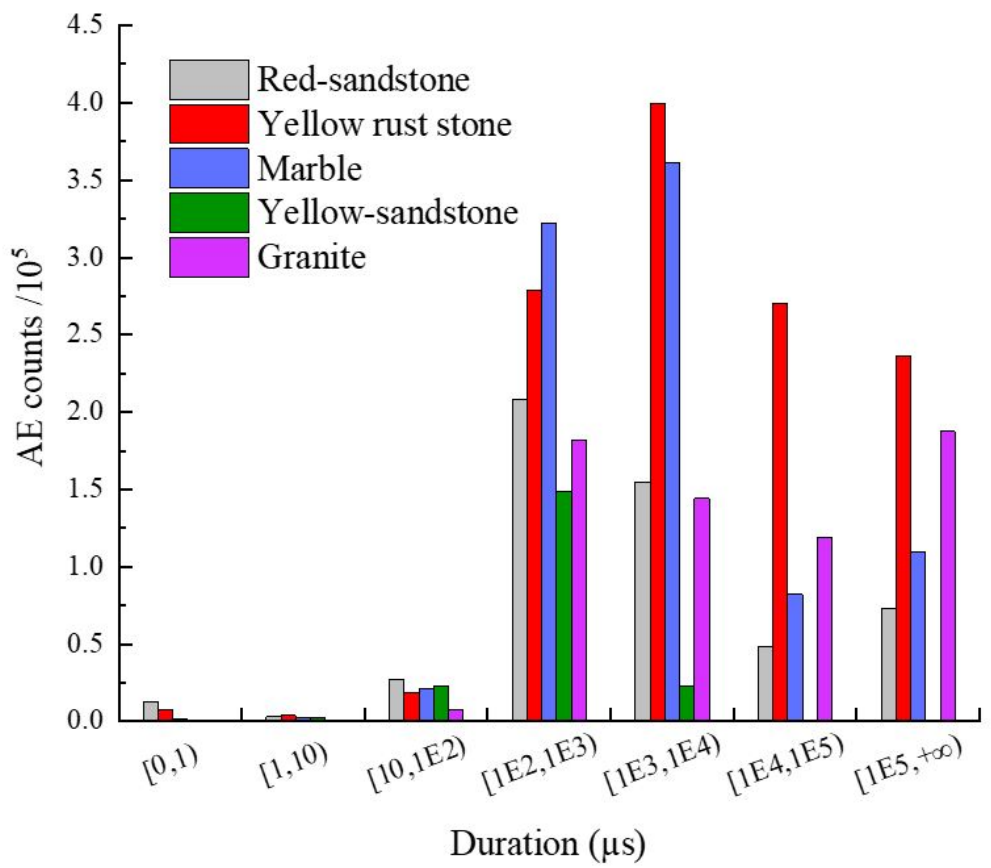

Figure $9 \mathrm{AE}$ duration distribution characteristics of three-point bending rock beams of different lithologies.

During the specimens loading process, the energy stored inside the rock beams will be released as the crack develops and expands. The amount of energy released can be reflected by AE energy. Figure 10(a) shows the AE energy release process of different lithological rock beams. The AE energy release process of each rock beams shows a step increase. The AE energy release process of the sandstone is relatively gentle. The total AE energy released by the redsandstone and yellow-sandstone specimens is about $2.40 \times 10^{9} \mathrm{~ms} \cdot \mathrm{mV}$ and $1.77 \times 10^{9} \mathrm{~ms} \cdot \mathrm{mV}$, respectively. For rock beams with greater strength, such as granite, the AE energy of the specimens increases sharply when the specimen fails. The total AE energy is $3.98 \times 10^{10} \mathrm{~ms} \cdot \mathrm{mV}$, which is 22.5 times that of the yellow-sandstone rock beam. The AE energy distribution of different lithologies is also different, as shown in Figure 10(b). The AE energy of the two kinds of the sandstone is concentrated in $100 \sim 1000 \mathrm{~ms} \cdot \mathrm{mV}$, while the $A E$ energy of the granite and the yellow rust stone is concentrated above $10^{6} \mathrm{~ms} \cdot \mathrm{mV}$. This shows that the AE energy of low-strength rock beams is mainly concentrated in the low-energy range, and high-strength rock beams also have AE counts in the high-energy range.

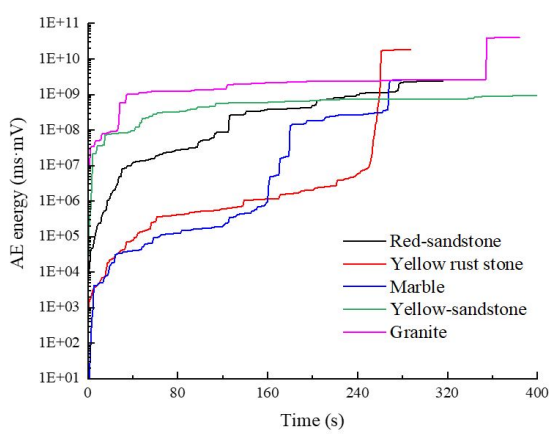

(a)

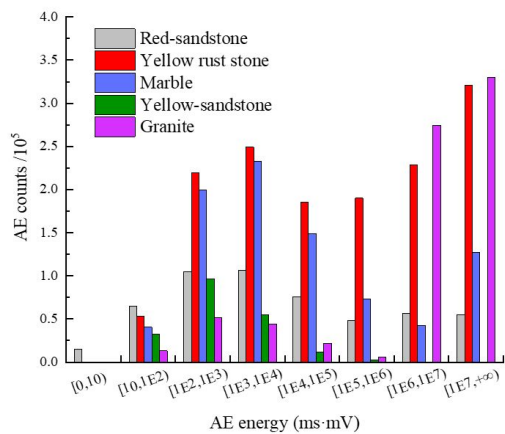

(b)

Figure $10 \mathrm{AE}$ energy characteristics of three-point bending rock beams with different lithologies: (a) AE energy evolution characteristics; (b) AE energy distribution characteristics. 
The RA value ( $R A=$ rise-time/ peak amplitude) changes with AF ( $A F=$ ring down counts/ duration) in the $A E$ signals and carries important information, which can be used to distinguish different crack modes (Li et al. 2020). Higher AF and lower RA represent tensile failure, and lower AF and higher RA represent shear failure. The AF values of the five lithological specimens are all between 0 and $1000 \mathrm{kHz}$, and there are very few points higher than $800 \mathrm{kHz}$. Based on the classification criteria in the literature (Du et al. 2020), the proportions of different types of cracks are roughly calculated, as shown in Figure 11. Most of the cracks in the three-point bending specimens are tensile cracks, and the shear cracks account for only a very small proportion. For example, the shear cracks of granite rock beam account for only $0.31 \%$. It can be seen from Figure 11(a) and (d) that the proportion of tensile cracks in red-sandstone and yellow-sandstone are $91.98 \%$ and $88.91 \%$, which are significantly lower than that of the other three rock beams. Since the tensile strength of two kinds of sandstones is very low, the proportion of tensile cracks in their failure process is very small. It is worth noting that the proportion of tensile cracks is roughly positively correlated with the elastic modulus of the rock. It shows that the greater elastic modulus of the rock beam, the stronger ability of resistance to deformation. When the rock beam is fractured by bending load, the friction and slip action between particles is weaker, so the tensile cracks accounts for a larger proportion.

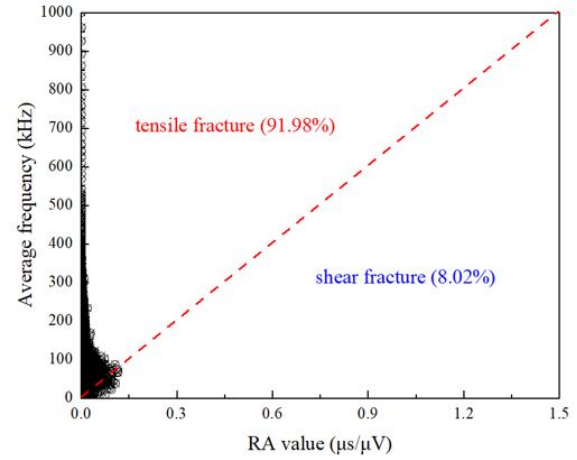

(a)

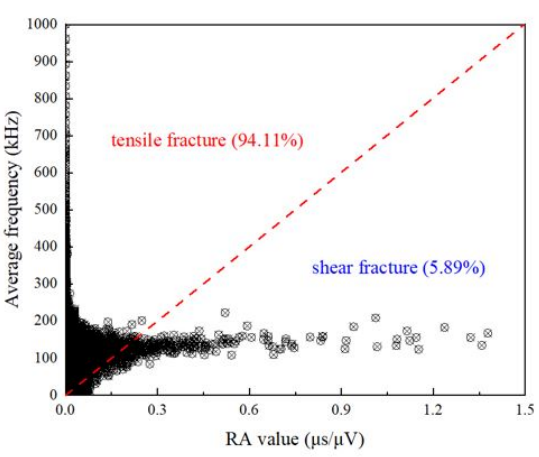

(b)

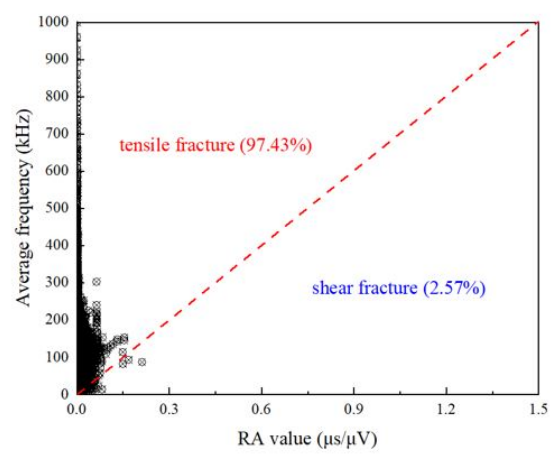

(c)

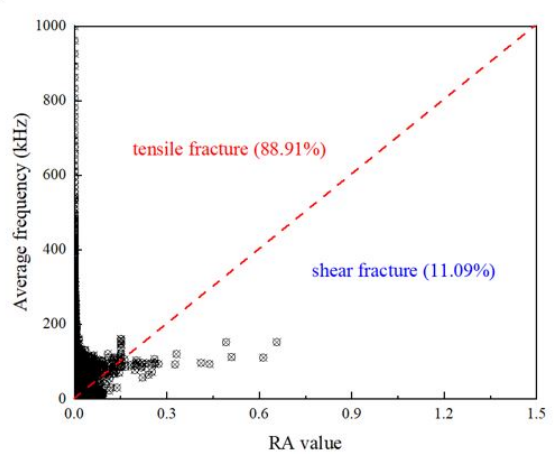

(d)

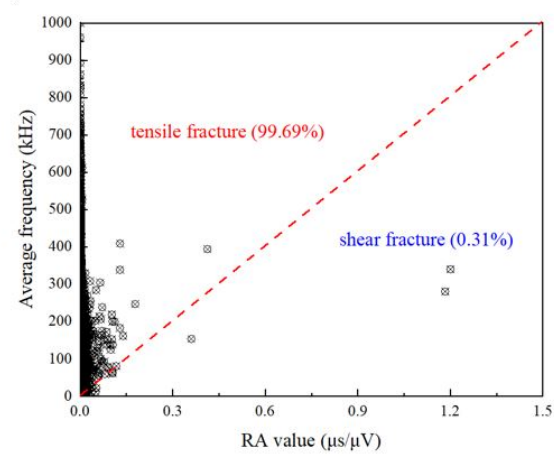

(e)

Figure 11 RA-AF distribution of three-point bending rock beams with different lithologies: (a) red sandstone; (b) yellow rust stone; (c) marble; (d) yellow sandstone; and (e) granite.

\subsection{Influence of rock beam thickness}

In order to analyze the influence of thickness on the AE characteristics of rock beams, Figure 12 shows the evolution of AE counts of the yellow rust stone specimens with different thicknesses. Similarly, the data is normalized and divided into stages. The five stages of $A E$ counts in the process of rock beam loading are highly consistent with the evolution of the load-deflection curve. The calm stage of $A E$ corresponds to the crack compaction stage, during which almost no $A E$ counts are observed. Then, after the rock beam passes through the elastic deformation stage and the crack propagation stage, the AE counts continues to increase, during which the micro-cracks inside the rock beams begin to develop. When the internal cracks in the rock beam develop for a period of time, it enters the unsteady crack propagation stage, the load reaches the peak, and the number of $A E$ counts reaches the maximum. After that, the rock beam will be fractured. Due to the friction of the crack section, a large number of $A E$ counts will still be generated at this stage, but overall the trend is that the rate of $\mathrm{AE}$ counts gradually decreases. 


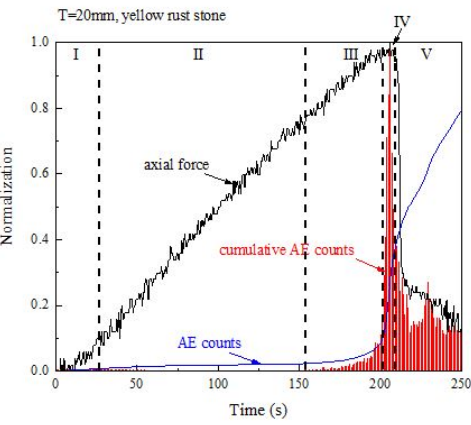

(a)

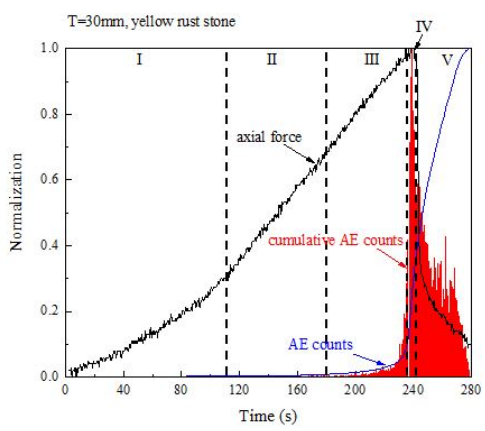

(b)

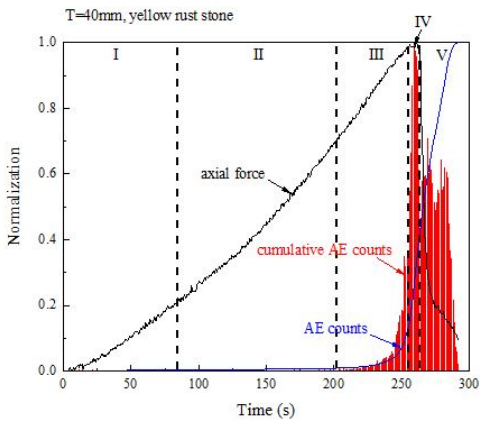

(c)

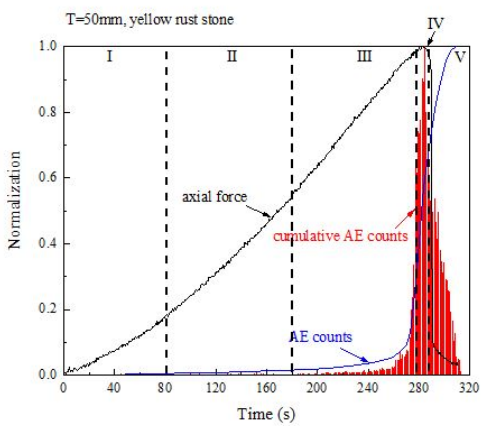

(d)

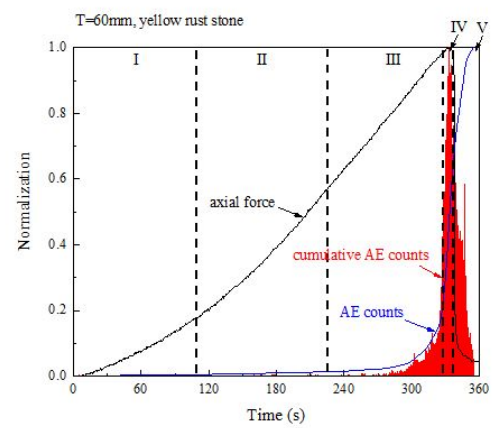

(e)

Figure $12 \mathrm{AE}$ evolution characteristics of three-point bending rock beams with different thickness: (a) 20mm; (b) 30mm; (c) 40mm; (d) $50 \mathrm{~mm}$; and (e) $60 \mathrm{~mm}$.

Figure 13 shows the distribution of $A E$ amplitudes of rock beams with different thicknesses. There are differences in the AE amplitude distribution of rock beams with different thicknesses. When the thickness of the rock beam is $20 \mathrm{~mm}$, the amplitude range with the most $A E$ counts is $50 \sim 65 \mathrm{~dB}$. When the thickness of the rock beam is $30 \mathrm{~mm}$, this range becomes 55 70 dB. When the thickness of the rock beam is $60 \mathrm{~mm}$, the amplitude range with the most $A E$ counts has exceeded $90 \mathrm{~dB}$. This shows that as the thickness of the rock beam increases, more high-amplitude $A E$ events occur, and the rock beam failure becomes more severe.

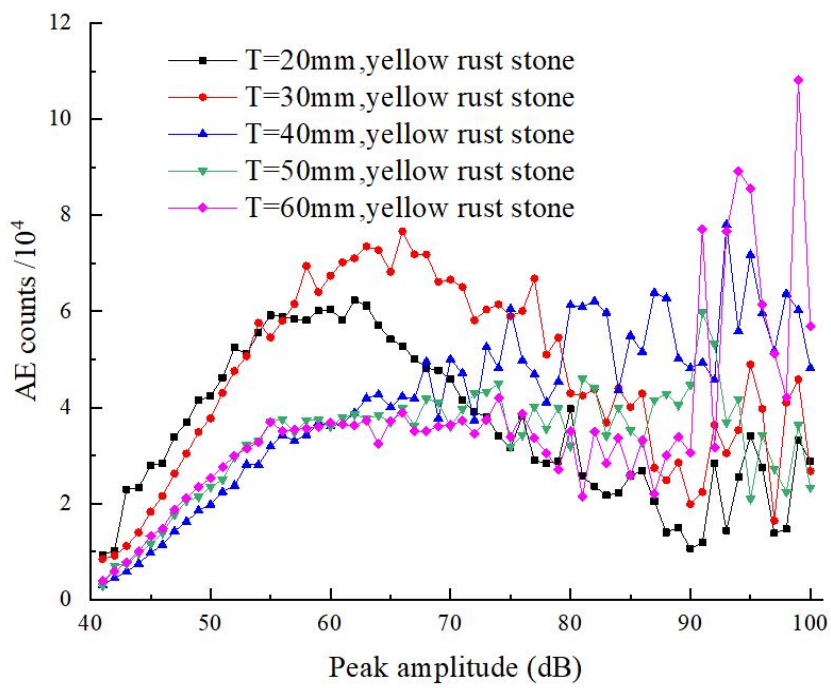

Figure $13 \mathrm{AE}$ peak amplitude distribution characteristics of three-point bending rock beams of different thickness.

Figure 14 shows the distribution of $A E$ duration of rock beams with different thicknesses. As shown in Figure 14, the $A E$ duration distribution laws of rock beams with different thicknesses are roughly similar, and the duration of more $A E$ events is between $10^{3} \sim 10^{4} \mu \mathrm{s}$. With the increase of the thickness, duration less than $100 \mu \mathrm{s}$ and greater than $100 \mu \mathrm{s}$ appeared almost opposite trends. More AE counts appeared in the duration greater than $100 \mu \mathrm{s}$, while the opposite was 
observed in the duration less than $100 \mu \mathrm{s}$. This shows that as the thickness of the rock beam increases, the duration of the AE signals gradually increases.

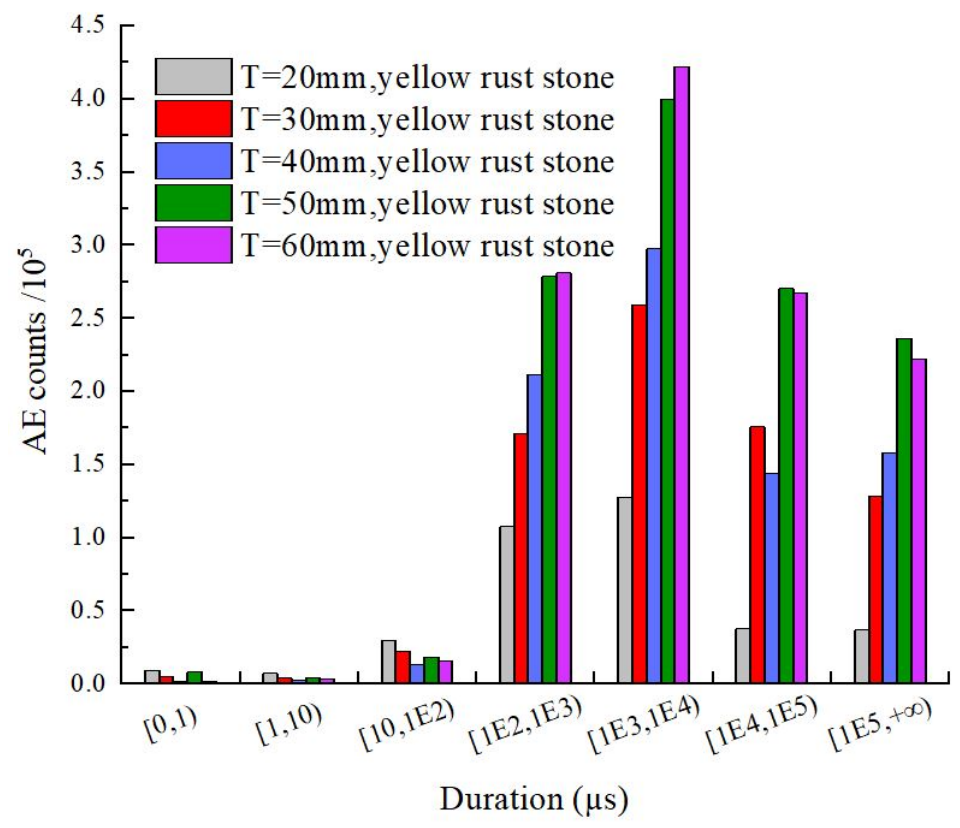

Figure $14 \mathrm{AE}$ duration distribution characteristics of three-point bending rock beams of different thickness.

Figure 15 shows the AE energy release processes of rock beams with different thicknesses, which are roughly similar, and they are almost unchanged in the early stage of loading and increase sharply when the specimen failed. As the thickness of the rock beam increases, the explosion stage of $A E$ energy is relatively lagging, and $A E$ energy value gradually increases. The total AE energy released by the $20 \mathrm{~mm}$ and $60 \mathrm{~mm}$ thick rock beams is $8.01 \times 10^{9} \mathrm{~ms} \cdot \mathrm{mV}$ and $2.14 \times 10^{10}$ $\mathrm{ms} \cdot \mathrm{mV}$ with an increase of $167.2 \%$. The AE energy distribution of rock beams with different thicknesses has regularity, as shown in Figure 12. The rock beam with a thickness of $20 \mathrm{~mm}$ has the most AE counts when the AE energy is in the range of $10^{3} \sim 10^{4} \mathrm{~ms} \cdot \mathrm{mV}$. When the thickness increases to $60 \mathrm{~mm}$, the $A E$ counts with $A E$ energy above $10^{7} \mathrm{~ms} \cdot \mathrm{mV}$ are the most. It shows that with the gradual increase in thickness of rock beams, the AE counts are concentrated in the highenergy range, and the total AE energy released is also greater.

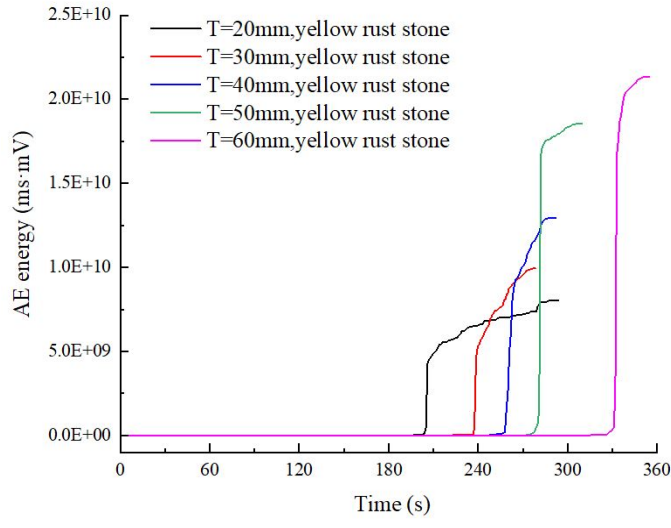

(a)

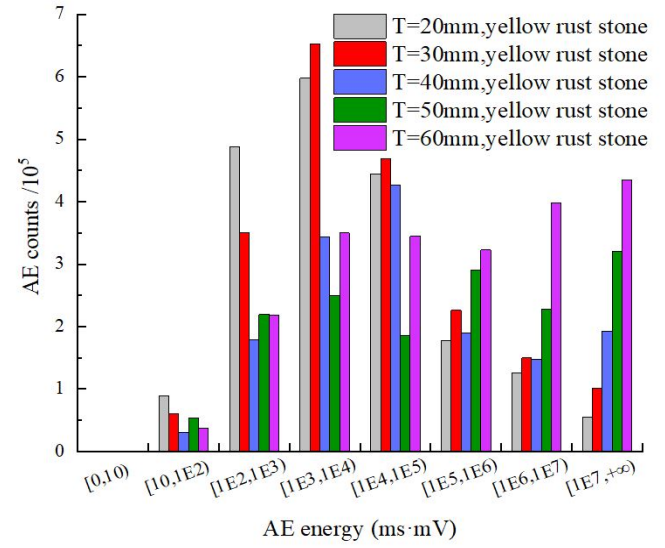

(b)

Figure $15 \mathrm{AE}$ energy characteristics of three-point bending rock beams with different thickness: (a) AE energy evolution characteristics; (b) AE energy distribution characteristics. 


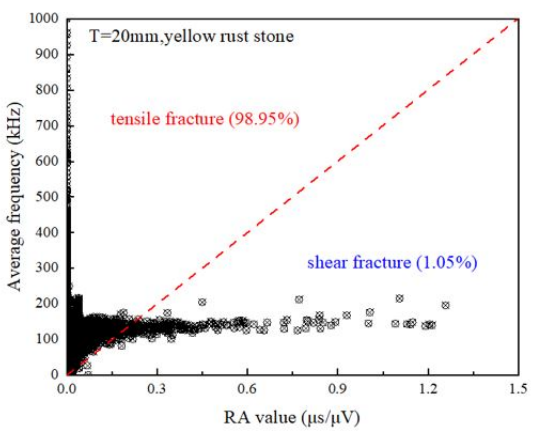

(a)

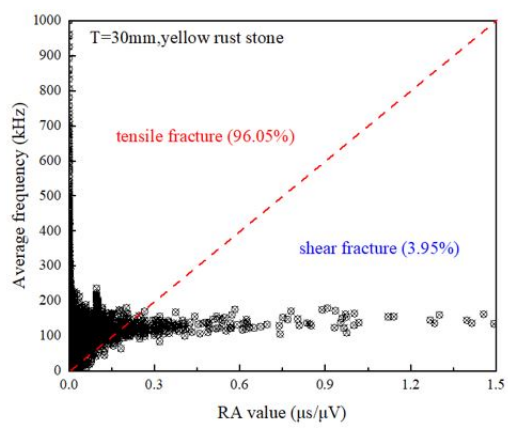

(b)

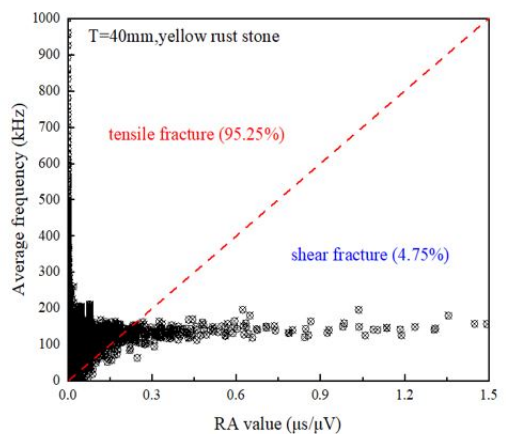

(c)

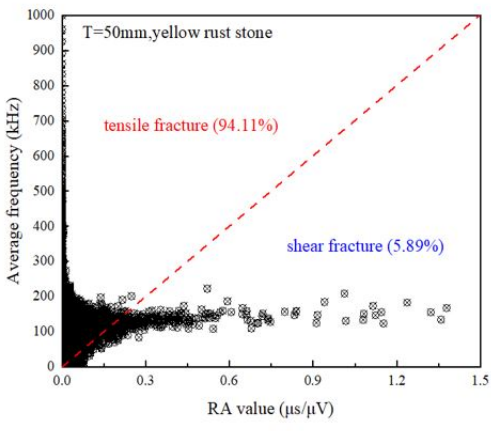

(d)

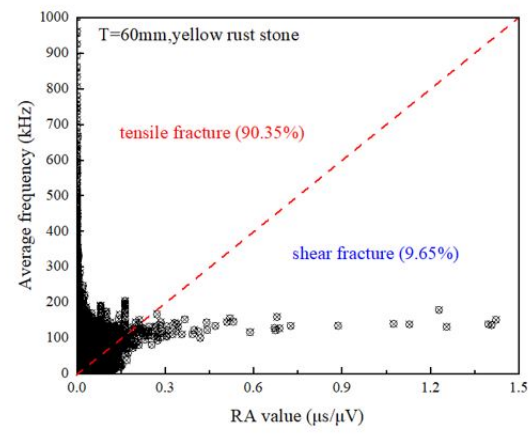

(e)

Figure 16 RA-AF distribution of three-point bending rock beams with different thickness: (a) 20mm; (b) $30 \mathrm{~mm}$; (c) 40mm; (d) 50mm; and (e) $60 \mathrm{~mm}$.

Figure 16 shows the AF-RA distributions of rock beams with different thicknesses, which are also roughly similar, and the average frequency is concentrated around $120 \mathrm{kHz}$. The proportion of tensile cracks in the rock beam has a negative correlation with the thickness. The tensile cracks of the rock beam with a thickness of $20 \mathrm{~mm}$ are $98.95 \%$. When the thickness of the rock beam increases to $60 \mathrm{~mm}$, the proportion of tensile cracks is reduced to $90.35 \%$. This is because as the thickness increases, the fracture area of the rock beam increases, and the frictional slip between the fracture surfaces becomes more intense. More AE signals of shear cracks are collected, which reduces the occupancy rate of tensile cracks.

\section{DISCUSSION ON THE INFLUENCE OF LITHOLOGY AND THICKNESS ON THE ENERGY RELEASED BY ROOF RACTURE}

According to this study, the influence of lithology and thickness on the energy released by rock beam fracture can be attributed to two aspects: energy released and peak load of fracture. Figure 17(a) shows the total energy released during the fracture of the rock beam. Rock beams with different lithologies and thicknesses released a total of

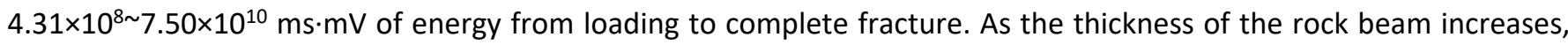
the total AE energy gradually increases. Figure $17(\mathrm{~b})$ shows the peak AE energy released during the rock beam fracture

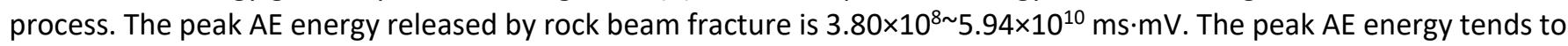
increase with the increase of rock beam thickness. It is worth noting that the total AE energy of the yellow rust stone specimens under the same thickness is less than that of the marble specimens, but the peak AE energy is consistently larger than that of the marble specimens. This might be related to the mechanical characteristics of the rock. The elastic modulus of the yellow rust stone used in the test is greater than that of the marble, but the tensile strength is lower than that of the marble. According to the results of the five sets of tests, the total AE energy is positively correlated with the tensile strength of the rock. Therefore, the tensile strength of the rock might be the main influencing factor of the total AE energy. 


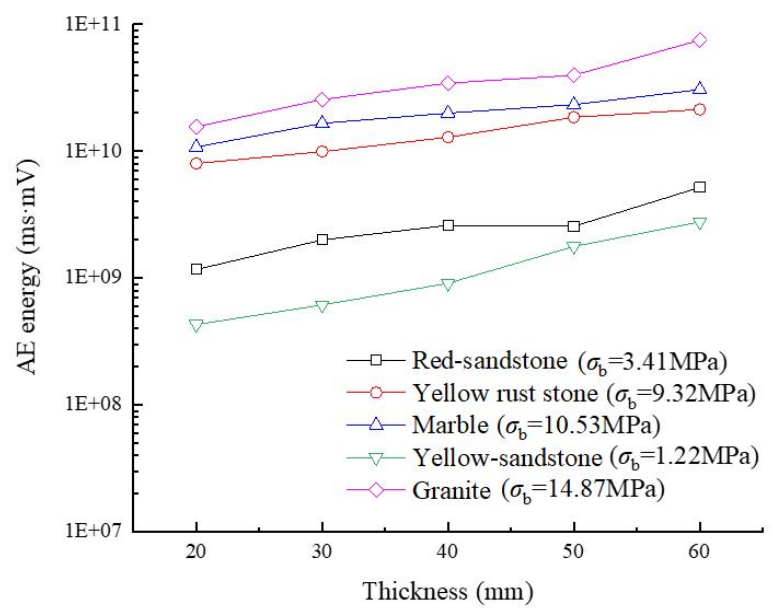

(a)

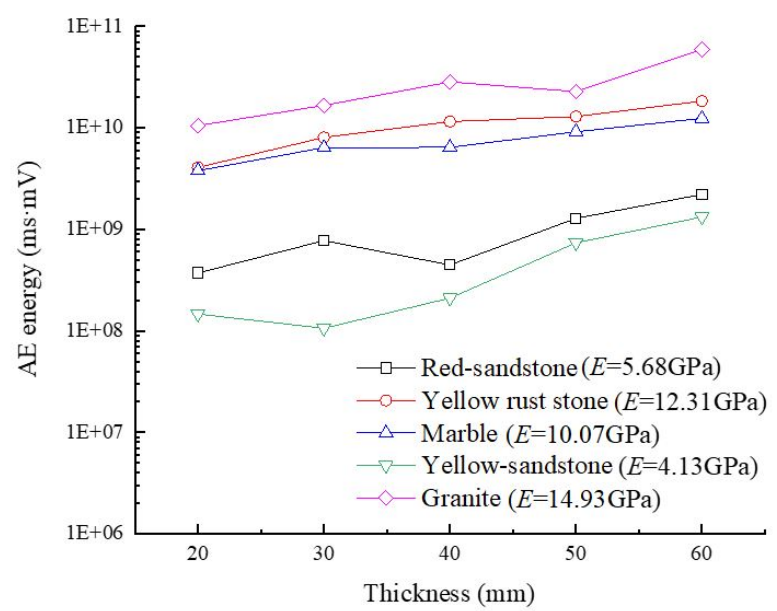

(b)

Figure $17 \mathrm{AE}$ energy released of three-point bending rock beams fracture: (a) total energy; (b) peak energy.

In order to characterize the intensity of energy released when the rock beam is fractured, the percentage of peak energy during the failure process of the specimen is proposed.

$k=\frac{V_{\mathrm{rp}}}{V_{\mathrm{r}}}$

In Eq.(2), $V_{r p}$ is the peak AE energy of the specimen fracture, and $V_{r}$ is the total AE energy of the specimen fracture.

According to Eq.(2), the percentage peak energy of rock beams with different lithologies and thicknesses are calculated, and the calculation results are shown in Figure 18. As the thickness increases, the percentages of peak energy of the rock beams also increases to varying degrees. When the thickness of the rock beam increases from $20 \mathrm{~mm}$ to $60 \mathrm{~mm}$, the percentages of peak energy increases by $15.9 \%$ to $68.9 \%$. The percentage peak energy with different lithologies are quite different, and the distribution range is $17.12 \%$ to $89.27 \%$. The average values of five kinds of lithological are $32.73 \%$ (yellow-sandstone), 36.09\% (red-sandstone), 37.11\% (marble), 70.30\% (granite), and $75.44 \%$ (yellow rust stone), respectively, which show a positive correlation with the elastic modulus of rock. The only anomaly appears between yellow rust stone and granite, which may be related to the closeness of the elastic modulus of the two rock lithologies. Therefore, the increase of thickness and elastic modulus will cause more energy to be released when the rock beam fractures.

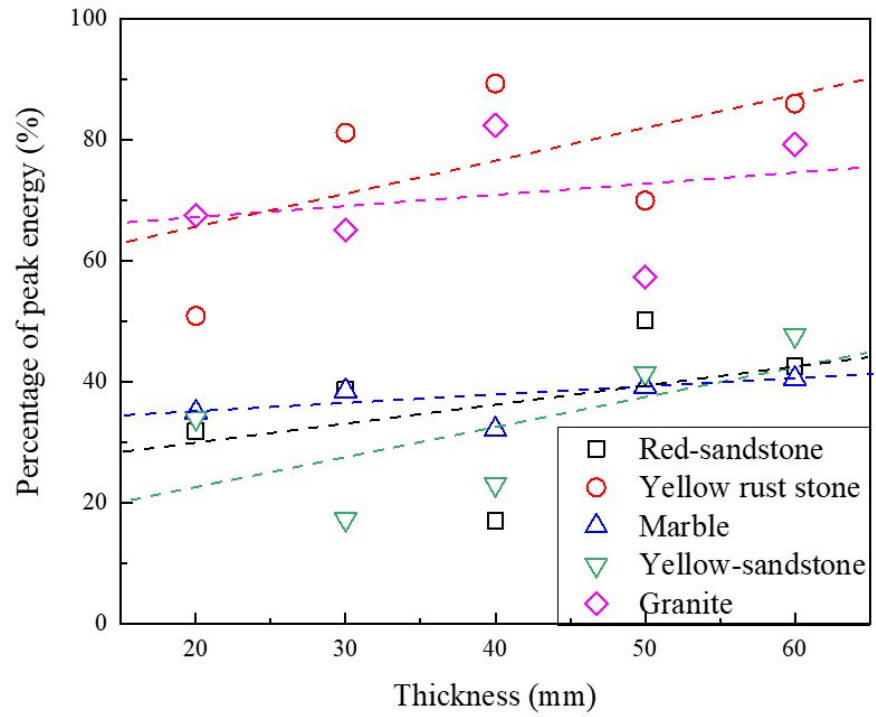

Figure 18 Percentage of peak energy of three-point bending rock beam. 
In addition, the lithology and thickness will affect the peak load of beam fracture. When the rock beam is bent, the maximum tensile stress appears at the midpoint of the bottom surface. According to Eq.(1), the peak load when the beam fractures is:

$$
F_{\max }=\frac{2\left[\sigma_{\mathrm{b}}\right] b h^{2}}{3 l}
$$

In Eq.(3), $\left[\sigma_{b}\right]$ is the tensile strength of the rock.

Obviously, tensile strength and thickness determine the difficulty of the beam fracture. However, in the actual process of coal mining, the parameters of the roof rock layer are inherent. In other words, roofs with different geological conditions have different limit spans before fracturing. The greater the thickness and tensile strength of the rock beam, the longer the limit span when it fractures, and the more energy it releases. Therefore, when there is a thick rock layer or a hard rock layer in the roof, special attention should be paid to the damage of this part of formation. When necessary, measures such as reducing the thickness of the roof (such as cutting the roof) or reducing the strength of the roof (such as pre-crack drilling) should be taken to improve the safety of coal mining.

\section{CONCLUSION}

Three-point bending tests of rock beams with different lithologies and thicknesses were carried out. The shape of the load-deflection curve and stress-strain curve of the rock beams are related to the lithology. The tensile strength and maximum tensile strain of rock beams show obvious size effect. The tensile strength and maximum tensile strain are negatively correlated with the thickness of the rock beam.

The AE parameters characteristics during the fracture process of rock beams are analyzed. The evolution process of $\mathrm{AE}$ includes calm stage, development stage, incremental stage, explosive stage and residual stage, and the energy release process shows a step increase. Rock beams with small elastic modulus have a longer AE development stage, with more $A E$ counts before the peak, and less energy released. Different lithology will cause an order of magnitude difference in the energy released by the fracture of rock beams, while the thickness has not so much influence.

The AE signal intensity during the fracture process of rock beams are analyzed. The AE amplitude distribution of rock beams has three typical characteristics: 'low-low-low', 'high-low-high' and 'high-high-high'. With the increase in the strength and thickness of the rock beam, the AE phenomenon becomes stronger during fracture, more high-amplitude $A E$ events appear, and the duration of the $A E$ signal becomes longer.

According to the distribution of RA and AF of the AE signals, the crack mode of the rock beams are analyzed. The $A E$ average frequency of rock beam specimens is mostly concentrated below $800 \mathrm{kHz}$. Most of the cracks after rock beam fracture are tensile cracks, accounting for $99.69 \%$ of granite. The proportion of tensile cracks is positively correlated with the elastic modulus of the rock, and roughly negatively correlated with the thickness of the rock beam.

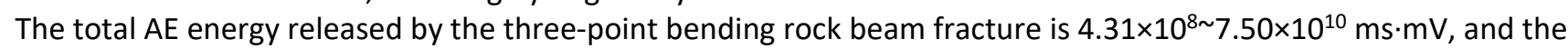
peak AE energy range is $3.80 \times 10^{8 \sim} 5.94 \times 10^{10} \mathrm{~ms} \cdot \mathrm{mV}$. The percentage of peak energy that characterizes the intensity of energy release during fracture is proposed. The coefficient ranges from $17.12 \%$ to $89.27 \%$, which is roughly positively correlated with rock thickness and elastic modulus. Although the load threshold is higher when a thick and hard roof breaks, it releases more energy when it fractures. When necessary, measures such as reducing the thickness of the roof (such as cutting the roof) or reducing the strength of the roof (such as pre-crack drilling) are taken to improve the safety of coal mining.

\section{Acknowledgments}

This research was supported by Major Scientific and Technological Innovation Project of Shandong Provincial Key Research Development Program (No. 2019SDZY02), Major Program of Shandong Provincial Natural Science Foundation (No. ZR2019ZD13), National Natural Science Foundation of China (No. 51904165), State Key Laboratory of Water Resource Protection and Utilization in Coal Mining (No. SHGF-16-25), and the Climbling Project of Taishan Scholar in Shandong Province(No. tspd20210313). 
Author's Contribuitions: Conceptualization, Tong-bin Zhao; Data curation, Tong-bin Zhao and Peng-fei Zhang; Investigation, Wei-yao Guo and Ya-xun Xiao; Methodology, Tong-bin Zhao and Wei-yao Guo; Visualization, Yong-qiang Zhao; Writing - original draft, Peng-fei Zhang and Wei-yao Guo; Writing - review \& editing, Xiang Sun.

Editor: Rogério José Marczak

\section{References}

Zhao, T.B., Guo, W.Y., Tan, Y.L., Yin, Y.C., Cai, L.S., Pan, J.F. (2018a). Case studies of rock bursts under complicated geological conditions during multi-seam mining at a depth of 800m. Rock Mechanics and Rock Engineering 51(5): 1539-1564. https://doi.org/10.1007/s00603-018-1411-7

Zhao, T.B., Guo, W.Y., Tan, Y.L., Lu, C.P., Wang, C.W. (2018b). Case histories of rock bursts under complicated geological conditions. Bulletin of engineering geology and the environment 77(4): 1529-1545. https://doi.org/10.1007/s10064-017-1014-7

Zhao, T.B., Xing, M.L., Guo, W.Y., Wang, C.W., Wang, B. (2021). Anchoring effect and energy-absorbing support mechanism of large deformation bolt. Journal of Central South University 28(2): 572-581. https://doi.org/10.1007/s11771-021-4622-0

Pan, Y.S., Li, Z.H., Zhang, M.T. (2003). Distribution, type, mechanism and prevention of rockbrust in china. Chinese Journal of Rock Mechanics and Engineering 22(11): 1844-1851. [In Chinese] https://doi.org/10.3321/j.issn:1000-6915.2003.11.019

Lu, C.P., Yang, L., Nong, Z., Zhao, T.B., Wang, H.Y. (2018). In-situ and experimental investigations of rockburst precursor and prevention induced by fault slip. International Journal of Rock Mechanics and Mining Sciences 108: 86-95. https://doi.org/10.1016/j.ijrmms.2018.06.002

Yu, Y., Geng, D.X., Tong, L.H., Zhao, X.S., Diao, X.H., Huang, L.H. (2018). Time fractal behavior of microseismic events for different intensities of immediate rock bursts. International Journal Of Geomechanics 18(7): 06018016.

https://doi.org/10.1061/(ASCE)GM.1943-5622.0001221

Hu, S.C., Tan, Y.L., Ning, J.G., Guo, W.Y., Liu, X.S. (2017). Multiparameter monitoring and prevention of fault-slip rock burst. Shock and Vibration 2017: 7580109. https://doi.org/10.1155/2017/7580109

Tan Y.L., Wang Z.H., Liu X.S., Wang C.W. (2021). Estimation of dynamic energy induced by coal mining and evaluation of burst risk. Journal of China Coal Society 46(01): 123-131. [In Chinese] https://doi.org/10.13225/j.cnki.jccs.2021.0010

Guo, W.Y., Qiu, Y., Zhao, T.B., Tan, Y.L., Chen, W.G. (2019a). Influence of the variable stoping speed on the occurrence mechanism of rock burst. Geomatics, Natural Hazards and Risk 10(1): 2094-2105. https://doi.org/10.1080/19475705.2019.1683083

Marcak, Henryk. (2012). Seismicity in mines due to roof layer bending. Archives of Mining Sciences 57(1): 229-250. https://doi.org/10.2478/v10267-012-0016-3

Zhao, T.B., Guo, W.Y., Yu, F.H., Tan, Y.L., Huang, B., Hu, S.C. (2018c). Numerical investigation of influences of drilling arrangements on the mechanical behavior and energy evolution of coal models. Advances in Civil Engineering 2018: 3817397. https://doi.org/10.1155/2018/3817397

Yang, S.T., Hu, X.Z., Wu, Z.M. (2011). Influence of local fracture energy distribution on maximum fracture load of three-pointbending notched concrete beams. Engineering Fracture Mechanics 78(18): 3289-3299. https://doi.org/10.1016/j.engfracmech.2011.09.019

Zhou, X.P., Qian, Q.H., Yang, H.Q. (2011). Rock burst of deep circular tunnels surrounded by weakened rock mass with cracks. Theoretical \& Applied Fracture Mechanics 56(2): 79-88. https://doi.org/10.1016/j.tafmec.2011.10.003

Lu, C.P., Liu, Y., Liu, G.J., Zhao, T.B. (2019). Stress evolution caused by hard roof fracturing and associated multi-parameter precursors. Tunnelling and Underground Space Technology 84: 295-305. https://doi.org/10.1016/j.tust.2018.11.031

Guo, W.Y., Zhao, T.B., Tan, Y.L., Yu, F.H., Hu, S.C. (2017). Progressive mitigation method of rock bursts under complicated geological conditions - sciencedirect. International Journal of Rock Mechanics and Mining Sciences 96: 11-22. https://doi.org/10.1016/j.ijrmms.2017.04.011

Dong, W., Yang, D., Zhou, X.M., Kastiukas, G., Zhang, B.S. (2017). Experimental and numerical investigations on fracture process zone of rock-concrete interface. Fatigue \& Fracture of Engineering Materials \& Structures 40(5): 820-835.

https://doi.org/10.1111/ffe.12558 
Stavrakas, I., Triantis, D., Kourkoulis, S.K., Pasiou, E.D., Dakanali, I. (2016). Acoustic emission analysis of cement mortar specimens during three point bending tests. Latin American Journal of Solids and Structures 13(12): 2283-2297. https://doi.org/10.1590/1679-78252486

Ayatollahi, M.R., Dehghany, M., Kaveh, Z. (2013). Computation of v-notch shape factors in four-point bend specimen for fracture tests on brittle materials. Archive of Applied Mechanics 83(3): 345-356. https://doi.org/10.1007/s00419-012-0654-0

Efimov, V. (2011). Determination of tensile strength by the measured rock bending strength. Journal of Mining Science 47(5): 580586. https://doi.org/10.1134/S1062739147050066

Koudelka, P., Fila, T., Rada, V., Zlamal, P., D Kytyr. (2020). In-situ x-ray differential micro-tomography for investigation of waterweakening in quasi-brittle materials subjected to four-point bending. Materials 13(6): 1405.

https://doi.org/10.3390/ma13061405

Bing, Q.L., Einstein, H.H. (2017). Comparison of visual and acoustic emission observations in a four point bending experiment on barre granite. Rock Mechanics and Rock Engineering. 50(9): 2277-2296. https://doi.org/10.1007/s00603-017-1233-z

Du, F.Z., Pan, S.S., Li, D.S. (2018). Damage evaluation and failure mechanism analysis of steel tube confined reinforced-concrete columns by acoustic emission technology. Latin American Journal of Solids and Structures 15(11): e136 https://doi.org/10.1590/1679-78255339

Cao, P., Liu, W.R. (2020). Study on failure mechanical characteristics and damage constitutive model of sandstone with different numbers of holes. Latin American Journal of Solids and Structures 17(5): e287. https://doi.org/10.1590/1679-78256052

Wu, C., Gong, F.Q., Luo, Y. (2020). A new quantitative method to identify the crack damage stress of rock using AE detection parameters. Bulletin of engineering geology and the environment 80(1): 519-531. https://doi.org/10.1007/s10064-020-01932-6

Guo, W.Y., Yu, F.H., Qiu, Y., Zhao, T.B., Tan, Y.L. (2019b). Experimental investigation of the mechanical behavior of layer-crack specimens under cyclic uniaxial compression. Symmetry-Basel 11(4): 465. https://doi.org/10.3390/sym11040465

Guo, W.Y., Yu, F.H., Tan, Y.L., Zhao, T.B. (2019c). Experimental study on the failure mechanism of layer-crack structure. Energy Science \& Engineering 7(6): 2351-2372. https://doi.org/10.1002/ese3.407

Zhang, Y.S., Zuo, S.Y., Yu, B., Chen, S.W., Jia, J.N. (2019). Study on bending damage constitutive model and mechanical properties of limestone based on acoustic emission. Advances in Civil Engineering 2019: 2031520. https://doi.org/10.1155/2019/2031520

Zhang, H., Fu, D.H., Song, H.P., Kang, Y.L., Huang, G.Y., Qi, G., Li, J.Y. (2015). Damage and fracture investigation of three-point bending notched sandstone beams by DIC and AE Techniques. Rock Mechanics and Rock Engineering 48(3): 1297-1303. https://doi.org/10.1007/s00603-014-0635-4

Wang, H.J., Zhao, F., Huang, Z.Q., Yu, H.C., Niu, J.R., Zhang, P. (2018). Study on acoustic emission characteristics of sandstone under different fracture modes. Arabian Journal of Geosciences 11(24): 772. https://doi.org/10.1007/s12517-018-4115-0

Li, X.J., He, P.J., Tang, J.H., Chen, X.D. (2020). Experimental and numerical studies on fracture characteristics of notched granite beams under cyclic loading and unloading. The Journal of Strain Analysis for Engineering Design 56(1): 3-17. https://doi.org/10.1177/0309324720923218

Du, K., Li, X.F., Tao, M., Wang, S.F. (2020). Experimental study on acoustic emission (AE) characteristics and crack classification during rock fracture in several basic lab tests. International Journal of Rock Mechanics and Mining Sciences 133: 104411. https://doi.org/10.1016/j.ijrmms.2020.104411

Xi, X., Wu, X., Guo, Q.F., Cai, M.F. (2020). Modelling the crack initiation and propagation of notched rock beam under the threepoint bending load. Advances in Civil Engineering 2020: 8810023. https://doi.org/10.1155/2020/8810023

Zhao, Y.H., Wang, S.R., Zou, Z.S., Ge, L.L., Fang, C. (2018). Instability characteristics of the cracked roof rock beam under shallow mining conditions. International Journal of Mining Science and Technology 28(3): 437-444.

https://doi.org/10.1016/j.ijmst.2018.03.005

Ju, M., Wang, D., Shi, J., Li, J., Li, X. (2021). Physical and numerical investigations of bedding adhesion strength on stratified rock roof fracture with longwall coal mining. Geomechanics and Geophysics for Geo-Energy and Geo-Resources (2021)7:24. https://doi.org/10.1007/s40948-020-00209-2 